\title{
CARDIOVASCULAR MEDICINE
}

\section{Use of statins in the secondary prevention of coronary heart disease: is treatment equitable?}

\author{
F D A Reid, D G Cook, P H Whincup
}

Heart 2002;88:15-19

See end of article for authors' affiliations

\section{Correspondence to:}

Fiona Reid, Department of Public Health Sciences, St George's Hospital Medical School, Cranmer Terrace, London SW17 ORE, UK; freid@sghms.ac.uk

Accepted

5 December 2001

\begin{abstract}
Objective: To investigate possible inequities in the use of statins for people with coronary heart disease according to a wide range of social and clinical factors.

Design and setting: Cross sectional analysis of data from the Health Survey for England 1998, a population based survey.

Subjects: 760 adults with coronary heart disease.

Results: Only $19.9 \%$ of subjects with coronary heart disease were receiving lipid lowering drugs (151 of $760 ; 95 \%$ confidence interval $(\mathrm{Cl}) 17.0 \%$ to $22.7 \%$ ). The likelihood of receiving statins was greatly reduced for older age groups: compared with those aged less than 65 years, the odds of receiving statin treatment were $0.53(95 \% \mathrm{Cl} 0.35$ to 0.80$)$ for subjects aged $65-74$ years, and $0.11195 \% \mathrm{Cl}$ 0.06 to 0.21 ) for subjects aged 75 years and over. Statins were given less often to current cigarette smokers than to non-smokers (odds ratio $0.55,95 \% \mathrm{Cl} 0.32$ to 0.96 ), and to subjects with angina compared with those with a previous myocardial infarct (odds ratio $0.63,95 \% \mathrm{Cl} 0.43$ to 0.93 ). Lower levels of statin use were also seen with increasing time since diagnosis $(p=0.12)$. No clear associations were observed with social measures.

Conclusions: Important inequalities were found in the use of statins among people with coronary heart disease, which could not be justified by evidence from the large statin trials. Proactive policies are required to ensure that the vast majority of (if not all) patients with coronary heart disease are receiving statins, regardless of age, sex, social class, smoking status, type of coronary heart disease, or time since diagnosis.
\end{abstract}

S nce 1994 several large randomised clinical trials have established the effectiveness of lipid lowering drugs (particularly statins) in preventing cardiac mortality and non-fatal coronary events, in the context of both primary ${ }^{12}$ and secondary ${ }^{3-5}$ prevention, through the lowering of serum cholesterol. The average reduction in relative risk found in these studies was around $25-30 \%$ over five years, in subjects with and without pre-existing coronary heart disease. Treatment with lipid lowering drugs is therefore a particularly important tool in the secondary prevention of coronary heart disease, as greater absolute benefit will be achieved in patients with a high risk of further coronary events.

In 1997 the Standing Medical Advisory Committee (SMAC) produced guidelines recommending that patients with a history of myocardial infarction should receive statins if their total cholesterol concentration was $4.8 \mathrm{mmol} / \mathrm{l}$ or more, while patients with angina should receive statins if their total cholesterol was $5.5 \mathrm{mmol} / \mathrm{l}$ or more. ${ }^{6}$ In 1998 the joint British recommendations on prevention of coronary heart disease in clinical practice advised that all patients with coronary heart disease should be prescribed statins if their total cholesterol was $5.0 \mathrm{mmol} / \mathrm{l}$ or more, or if their low density lipoprotein (LDL) cholesterol was $3.0 \mathrm{mmol} / \mathrm{l}$ or more. ${ }^{7}$ The implications of these guidelines are that the vast majority of patients with coronary heart disease should be receiving treatment with statins. ${ }^{8}$ The National Service Framework for coronary heart disease, published in 2000, goes further by recommending that statins are prescribed for all patients with diagnosed coronary heart disease. ${ }^{9}$ Prescribing of statins has shown large increases in recent years ${ }^{810-12}$; nevertheless the use of statins in the treatment of patients with coronary disease remains well below recommended levels, ${ }^{8}{ }^{12}$ despite the strength of evidence for clinical effectiveness and the abundance of guidance.

The question arises as to whether the shortfall in the use of statins among people with coronary heart disease is more apparent in certain sections of society. Previous studies have observed variation in the prescribing of statins between different health authorities and general practices, ${ }^{10}{ }^{13}$ and according to patients' age and sex. ${ }^{813}{ }^{14}$ One study found no difference in statin prescribing between practices in areas of high and low deprivation. ${ }^{11}$ However, no research has thus far investigated the association of statin use with social factors relating to individual patients, such as social class and cigarette smoking, or with clinical factors such as type of coronary heart disease or time since diagnosis.

In the present study we used national data from the 1998 Health Survey for England ${ }^{15}$ to assess systematically the association between the uptake of lipid lowering drugs and a range of demographic and clinical variables, in order to investigate possible inequities in the way these drugs are prescribed.

\section{METHODS}

The Health Survey for England ${ }^{15}$ is a large annual household survey commissioned by the Department of Health, and structured to be representative of all households in England. Participants are visited at home on two occasions, with an initial administered questionnaire followed by a nurse visit, during which a single non-fasting blood sample is taken and information on prescribed medicines recorded. In 1998, 74\% of eligible households participated in the first stage of the survey. The total number of individuals interviewed was 19654 , including 15908 adults (aged 16 years or over) of whom $13586(85.4 \%)$ participated in the nurse visit.

\section{Variables}

Specific questions relating to cardiovascular disease were included in the 1998 survey. Subjects who reported having received a doctor's diagnosis of angina or myocardial

Abbreviations: $\mathrm{HDL}$, high density lipoprotein; LDL, low density lipoprotein; SMAC, Standing Medical Advisory Committee 


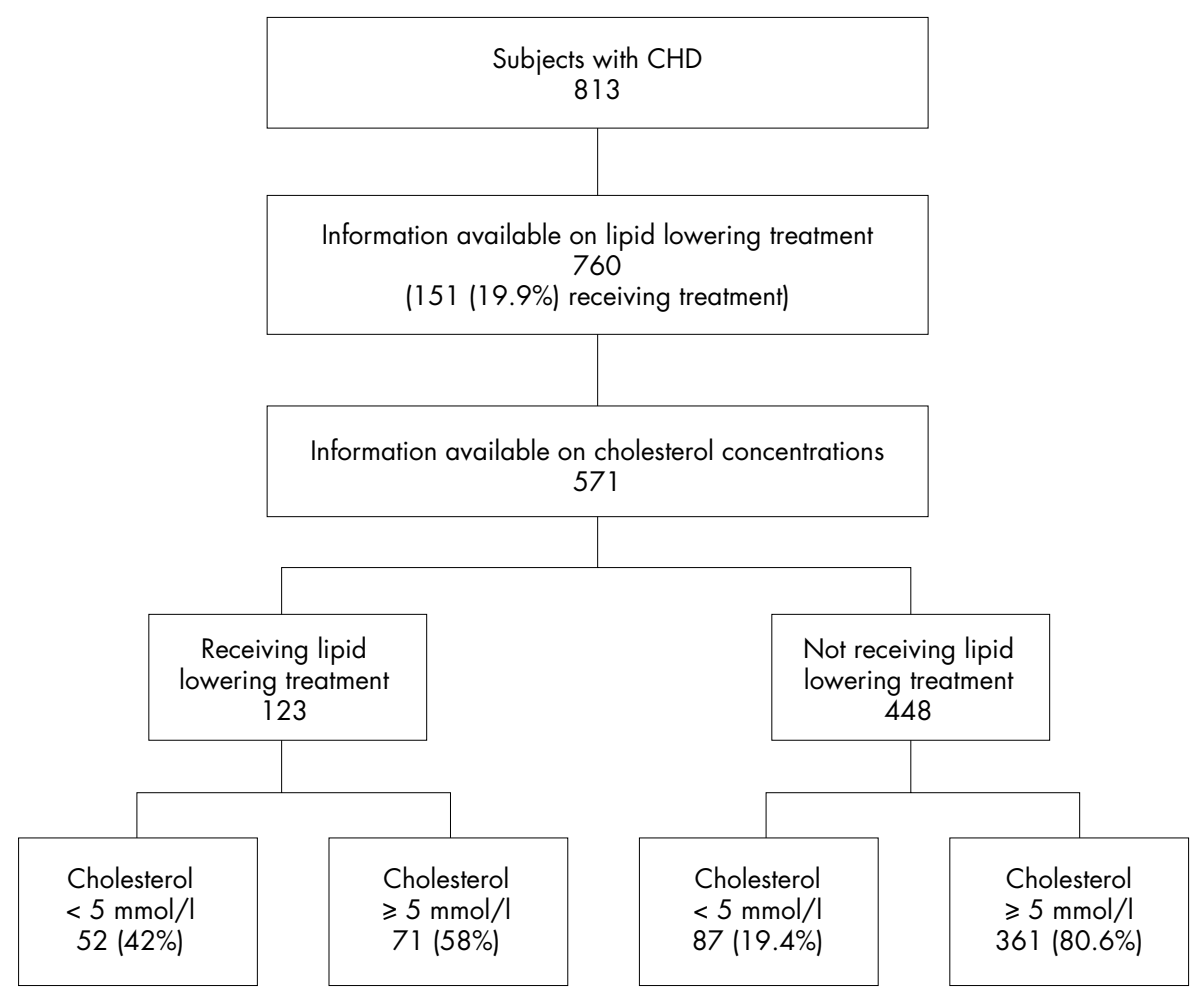

Figure 1 Number of subjects with coronary heart disease receiving lipid lowering treatment, and their cholesterol concentrations. infarction were classified as having coronary heart disease, and the time since diagnosis recorded. No specific data were available on revascularisation procedures. Information was obtained on prescriptions for lipid lowering drugs, comprising all those with a code of 2.12 in the British National Formulary. Separate identification of statins was not possible, but by 1998 statins comprised around $90 \%$ of all lipid lowering drugs prescribed..$^{12}$ Blood samples were subsequently analysed for total and high density lipoprotein (HDL) cholesterol concentrations. The survey also included detailed questions providing demographic, lifestyle, and clinical information. There were insufficient non-white subjects with coronary heart disease to allow analysis by ethnic origin.

\section{Analysis}

The relation between prescribing of lipid lowering drugs and various demographic, lifestyle, and clinical variables was investigated by logistic regression and presented as odds ratios, using SPSS for Windows, version $10 .^{16}$

\section{RESULTS}

Of the 13586 adults who had a nurse visit, 813 (6.0\%) had a confirmed diagnosis of coronary heart disease (fig 1). Information on use of lipid lowering drugs was available for 760 subjects with coronary heart disease, of whom 19.9\% ( $\mathrm{n}=151,95 \%$ confidence interval (CI) $17.0 \%$ to $22.7 \%$ ) were receiving lipid lowering treatment. For men, this rate was $22.3 \%$ (94/422), and for women $16.9 \%$ (57/338).

Serum cholesterol measurements were available for 571 of the 760 subjects. Of 448 subjects who had not been prescribed lipid lowering drugs, $81 \%(\mathrm{n}=361)$ had total cholesterol concentrations of $\geqslant 5 \mathrm{mmol} / \mathrm{l}$, for which cholesterol lowering treatment is indicated by the joint British recommendations. For the remaining 123 subjects who were taking lipid lowering drugs, $58 \%(\mathrm{n}=71)$ had a total cholesterol of $\geqslant 5 \mathrm{mmol} / \mathrm{l}$, implying that serum cholesterol was not adequately controlled in more than half of those treated.

According to the British guidelines, ${ }^{7} 85 \%$ of patients with coronary heart disease ( 484 of 571) should have been treated with statins; this figure was obtained by adding the 123 subjects already prescribed statins to the 361 untreated subjects whose total cholesterol measurement was above $5 \mathrm{mmol} / \mathrm{l}$. In practice, only $25.4 \%$ of these eligible subjects (123 of 484) were actually receiving lipid lowering treatment (95\% CI $21.5 \%$ to $29.3 \%$ ).

All 760 patients with coronary heart disease for whom information on lipid lowering drugs was available were included in the logistic regression analysis of factors related to treatment. The mean age of this group was 69 years (range 31-95), and 422 $(56 \%)$ were male. The odds of being prescribed lipid lowering drugs were significantly reduced with increasing age, no previous myocardial infarction, and current cigarette smoking (table 1), after adjustment for age and sex. Treatment odds were also lower the earlier the year of diagnosis of coronary heart disease, and for subjects living in rented accommodation (a possible social class proxy), although these variables just failed to reach significance at the $5 \%$ level.

All five of these variables were considered simultaneously in a multifactorial model to check for independence of their effects (table 2). Age, cigarette smoking, and type of coronary heart disease remained significant, while year of diagnosis and housing tenure lost significance $(\mathrm{p}=0.12$ and $\mathrm{p}=0.15$, respectively). Subjects aged $65-74$ years were half as likely to be receiving lipid lowering treatment compared with those aged under 65 years, and people aged 75 years and over were nine times less likely; current cigarette smoking reduced the chance of treatment by almost half; and those with angina alone had around a $60 \%$ chance of receiving treatment compared with those with a previous heart attack. These odds ratios remained very similar if year of diagnosis and housing tenure were removed from the model.

Sex, geographical region, diabetes, hypertension, family history of cardiovascular disease, body mass index, marital status, and other variables relating to social class were not significant in explaining the variation in statin prescribing.

\section{DISCUSSION}

In this study we have identified important inequalities in the prescribing of lipid lowering drugs for people with coronary heart disease, against a background of low levels of prescribing of these drugs overall. Patients are at a disadvantage for 


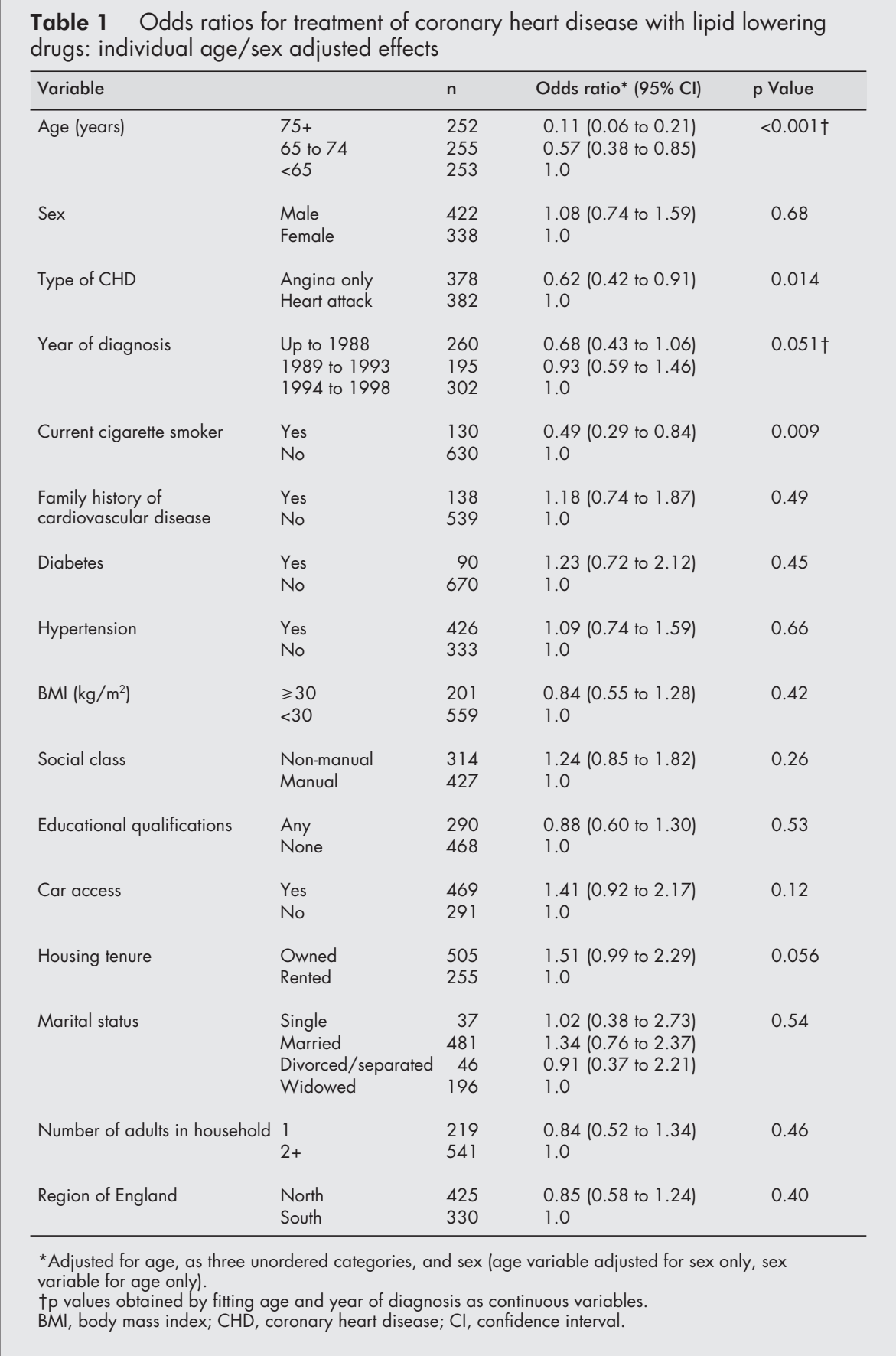

receiving lipid lowering treatment if they are elderly, have angina but no previous heart attack, or are smokers. There was also a suggestion that patients with a less recent diagnosis of coronary heart disease and those living in rented accommodation (consistent with lower social class) were less likely to be receiving treatment. Sex had no significant effect, once age differences had been controlled for.

\section{Strengths and limitations}

The Health Survey for England is large and well designed, providing nationally representative data. Information is provided on individuals rather than general practices, thus avoiding the risk of ecological fallacy and allowing stronger conclusions to be drawn. The definition of coronary heart disease depended on the patient's recall of a doctor's diagnosis; however, this question was asked as part of a rigorous structured interview, in the context of a range of questions on cardiovascular topics. The response rate to the survey was not $100 \%$, either to the initial interview or to the nurse visit, and this could have introduced bias.

As the available single non-fasting measurement of cholesterol would be less reliable than a repeated fasting value, and because we could not assume that all people currently receiving statin treatment were doing so as a result of a high cholesterol, we decided to look at inequalities among all people with coronary heart disease, not just those who appeared "eligible" according to British guidelines. This choice of method could have introduced bias if cholesterol concentrations were related to any of the explanatory variables investigated; however, there are no obvious reasons why cholesterol should be higher in those found to have increased rates of treatment (in particular non-smokers, or people under 65 years), and a comparison of mean cholesterol concentrations in untreated subjects supported this. 
Table 2 Odds ratios for treatment of coronary heart disease with lipid lowering drugs: multifactorial model

\begin{tabular}{|c|c|c|c|c|}
\hline Variable & & $\mathrm{n}$ & Odds ratio* $(95 \% \mathrm{CI})$ & $\mathrm{p}$ Value \\
\hline Age (years) & $\begin{array}{l}75+ \\
65 \text { to } 74 \\
<65\end{array}$ & $\begin{array}{l}250 \\
255 \\
252\end{array}$ & $\begin{array}{l}0.11(0.06 \text { to } 0.21) \\
0.53(0.35 \text { to } 0.80) \\
1.0\end{array}$ & $<0.001 \dagger$ \\
\hline Type of CHD & $\begin{array}{l}\text { Angina only } \\
\text { Heart attack }\end{array}$ & $\begin{array}{l}376 \\
381\end{array}$ & $\begin{array}{l}0.63(0.43 \text { to } 0.93) \\
1.0\end{array}$ & 0.019 \\
\hline Current cigarette smoker & $\begin{array}{l}\text { Yes } \\
\text { No }\end{array}$ & $\begin{array}{l}130 \\
627\end{array}$ & $\begin{array}{l}0.55(0.32 \text { to } 0.96) \\
1.0\end{array}$ & 0.037 \\
\hline Year of diagnosis & $\begin{array}{l}\text { Up to } 1988 \\
1989 \text { to } 1993 \\
1994 \text { to } 1998\end{array}$ & $\begin{array}{l}260 \\
195 \\
302\end{array}$ & $\begin{array}{l}0.72(0.46 \text { to } 1.14) \\
0.90(0.56 \text { to } 1.42) \\
1.0\end{array}$ & $0.12 \dagger$ \\
\hline Housing tenure & $\begin{array}{l}\text { Owned } \\
\text { Rented }\end{array}$ & $\begin{array}{l}504 \\
253\end{array}$ & $\begin{array}{l}1.38(0.90 \text { to } 2.12) \\
1.0\end{array}$ & 0.15 \\
\hline
\end{tabular}

\section{Age and sex inequalities}

Subgroup analyses of the large statin trials show an identical risk reduction in those aged under and over 65 years, ${ }^{17}{ }^{18}$ and therefore the almost twofold treatment disadvantage found here for those aged $65-74$ years has no scientific basis. Indeed patients aged over 65 years should derive greater benefit from statins in absolute terms, given that they have a higher baseline risk. The statin trials did not include patients aged over 75 years, so there is no direct evidence for the efficacy of statins in this age group. There may also be a fear of greater side effects occurring in the very elderly. Until current trials being conducted in the over $75 \mathrm{~s}$ settle these issues, individual clinical judgement must prevail. However, given the absence of any evidence suggesting that efficacy may decrease with age, a ninefold treatment differential compared with under 65 year olds seems unwarranted.

The effect of sex on statin prescribing became small and nonsignificant once age differences were taken into account (odds ratio $=1.08, \mathrm{p}=0.68$ ), albeit with a wide confidence interval. This is somewhat at variance with the recent study in the Trent region by Hippisley-Cox and colleagues ${ }_{1}^{14}$ which found a higher rate of treatment among men after adjusting for age and other factors (odds ratio 1.42, $\mathrm{p}<0.0001$ ). Possible reasons for this difference might include the different geographical areas studied, different sources of data (Hippisley-Cox obtained data from routine general practice records), and the exact method used to control for age, with which sex is strongly confounded.

\section{Smoking and social class inequalities}

Subgroup analyses of the large statin trials found statins to be equally effective in smokers and non-smokers. ${ }^{19}$ Therefore there is no clinical reason why smokers should be denied this treatment. Of course smokers could further improve their prognosis by giving up smoking, and treatment plans should continue to include advice on smoking cessation as well as on diet and exercise. However, there seems little justification for withholding a proven pharmacological intervention from this group, given the difficulties they face in relinquishing a strong, often life long, addiction. Whether statins are actually being denied to patients who continue to smoke, as previously reported for revascularisations, ${ }^{20}$ is not clear. It may be more likely that the reduced treatment levels reflect patient factors, as smokers are known to have lower average levels of attendance in primary care ${ }^{21}$ and have been shown to have decreased compliance with antihypertensive drug treatment. ${ }^{22}$

The influence of social class on treatment inequalities was unclear. People in rented housing seemed at a possible disadvantage, but other variables indicative of social status (car ownership, social class, educational qualifications) showed less of a link with lipid lowering treatment. The effect of housing tenure was modified by the inclusion of cigarette smoking in the same model-these two variables are strongly interrelated and it is difficult to differentiate their effects entirely. There are many examples of greater access to health care for the higher social classes, generally ascribed to better communication skills and awareness of treatment options; for coronary heart disease, in particular, a strong social gradient has been demonstrated for access to coronary artery bypass grafts and angioplasty. ${ }^{23}$ Conversely, no association with social class was found in a recent study of treatment for hypertension. ${ }^{24}$

\section{Type of coronary heart disease and year of diagnosis:} inequalities

It is perhaps unsurprising that statin treatment rates were lower in subjects whose coronary heart disease took the form of angina only, as the risk of coronary events will be lower in this group compared with those with previous myocardial infarction, and the SMAC guidelines indicate a higher cholesterol cut off for initiating treatment. However, angina patients still have a high absolute risk of acute coronary events. Unless prioritisation becomes necessary for allocation of resources, there seems no reason to withhold statins from patients with angina only.

Although not statistically significant, there was some suggestion that the odds of treatment were reduced the longer ago the diagnosis of coronary heart disease was made. A similar association has previously been reported for treatment of coronary heart disease with aspirin. ${ }^{25}$ There may be a reluctance to alter the treatment of patients who appear stable on their current drugs, and in particular those patients whose treatment was established before the dissemination of the statin trial results may be missing out. There is a need to review proactively the treatment of all patients with coronary heart disease in general practice.

\section{Overall uptake of statins}

The very low statin prescribing rate in people with coronary heart disease overall is a cause for concern, although this study was conducted in 1998 and rates may have increased since then. Further increases in the use of statins should hopefully be stimulated by the recently published National Service Framework for coronary heart disease. ${ }^{9}$ A recent study also highlighted the benefits of starting treatment as early as possible, with significant reductions in mortality if treatment was begun at the time of hospital discharge in patients admitted for 
unstable angina or myocardial infarction. ${ }^{26}$ Patients already prescribed statins should be monitored regularly, as the low degree of cholesterol control found in this study suggests problems either with compliance or with the choice or dose of the drug prescribed.

Barriers to a more widespread use of statins may include fears about the cost implications, particularly within general practice. If recommendations for primary prevention with statins are followed, ${ }^{67}$ this could indeed have huge budget implications; for secondary prevention, however, statins have been shown to be as cost effective as other widely accepted interventions such as angioplasty and coronary artery bypass grafts. ${ }^{27}{ }^{28}$ Perhaps rapid change in clinical practice is not to be expected; Fairhurst and Huby showed that the publication of strong scientific evidence on statins was insufficient in itself to alter treatment patterns among general practitioners, with practitioners requiring the further reassurance of a developing local consensus. ${ }^{29}$ However, it is to be hoped that sufficient time has now elapsed, and enough evidence been gathered, to convince clinicians in both primary and secondary care that statins should be prescribed for the vast majority of (if not all) patients with coronary heart disease, without regard to age, sex, social class, smoking status, nature of coronary heart disease, or time since diagnosis.

\section{ACKNOWLEDGEMENTS}

We thank the Data Archive and the depositors of the information for permission to use the data. Material from the Health Survey for England is Crown Copyright and has been made available by the Office for National Statistics, the Joint Health Surveys Unit of Social and Community Planning Research, and the Department of Epidemiology and Public Health at University College, London. Neither the depositors nor the Data Archive bear any responsibility for the analysis or interpretation of the data reported here.

\section{Authors' affiliations}

F D A Reid, D G Cook, P H Whincup, Department of Public Health Sciences, St George's Hospital Medical School, London SW 17, UK

\section{REFERENCES}

1 Shepherd J, Cobbe SM, Ford I, et al. Prevention of coronary heart disease with pravastatin in men with hypercholesterolemia. N Engl J Med 1995;333:1301-7.

2 Downs JR, Clearfield M, Weis S, et al. Primary prevention of acute coronary events with lovastatin in men and women with average cholesterol levels: results of AFCAPS/TexCAPS. JAMA 1998;279: 1615-22

3 Scandinavian Simvastatin Survival Study Group. Randomised trial of cholesterol lowering in 4444 patients with coronary heart disease: the Scandinavian simvastatin survival study (4S). Lancet 1994;344:1383-9.

4 Sacks FM, Pfeffer MA, Moye LA, et al. The effect of pravastatin on coronary events after myocardial infarction in patients with average cholesterol levels. N Engl J Med 1996;335:1001-9.

5 Long Term Intervention with Pravastatin in Ischaemic Disease (LIPID) Study Group. Prevention of cardiovascular events and death with pravastatin in patients with coronary heart disease and a broad range of initial cholesterol levels. N Engl J Med 1998;339:1349-57.
6 NHS Executive. Standing medical advisory committee on use of statins. London: Department of Health, 1997.

7 Wood D, Durrington P, Mclnnes P, et al. Joint British recommendations on prevention of coronary heart disease in clinical practice. Heart 1998;80(suppl 2):S1-29.

8 Primatesta P, Poulter NR. Lipid concentrations and the use of lipid lowering drugs: evidence from a national cross sectional survey. BM 2000;321:1322-5.

9 National Service Framework for Coronary Heart Disease. Modern standards and service models, 2000. London: HMSO, 2000.

10 Baxter C, Jones R, Corr L. Time trend analysis and variations in prescribing lipid lowering drugs in general practice. BM 1998;317:1134-5.

11 Packham C, Pearson J, Robinson J, et al. Use of statins in general practices, 1996-8: cross sectional study. BM 2000;320:1583-4.

12 Office for National Statistics. Key health statistics from general practice 1998. London: HMSO, 2000.

13 Majeed A, Moser K, Maxwell R. Age, sex and practice variations in the use of statins in general practice in England and Wales. J Public Health Med 2000:22:275-9.

14 Hippisley-Cox J, Pringle $M$, Crown N, et al. Sex inequalities in ischaemic heart disease in general practice: cross-sectional survey. BM 2001;322:832-4.

15 Erens B, Primatesta P, eds. Health survey for England. Cardiovascular disease '98, vol 2. Methodology and documentation. London: HMSO, 2000.

16 SPSS for Windows, release 10.0. Cary, NC: SPSS Inc, 1989-99.

17 NHS Centre for Reviews and Dissemination. Cholesterol and coronary heart disease: screening and treatment. Effective Health Care Bull 1998;4(1)

18 LaRosa JC, He J, Vupputuri S. Effect of statins on risk of coronary disease: a meta-analysis of randomized controlled trials. JAMA 1999;282:2340-6

19 Isles CG, Norrie J. Lipid lowering drugs for patients who continue to smoke? [editorial] Heart 2000;83:619-20.

20 Morris RW, McCallum AK, Walker M, et al. Cigarette smoking in British men and selection for coronary artery bypass surgery. Heart 1996;75:557-62

21 McCormick A, Fleming D, Charlton J. Morbidity statistics from general practice: fourth national study 1991-1992. London: OPCS, 1995.

22 Vaur L, Vaisse B, Genes N, et al. Use of electronic pill boxes to assess risk of poor treatment compliance: results of a large-scale trial. Am J Hypertens 1999;12:374-80.

23 Hippisley-Cox J, Pringle M. Inequalities in access to coronary angiography and revascularisation: the effect of deprivation and location of primary care services. Br J Gen Pract 2000;50:449-54.

24 Shah S, Cook DG. Inequalities in the treatment and control of hypertension: age, social isolation and lifestyle are more important than economic circumstances. J Hypertens 2001;19:1333-40.

25 McCallum AK, Whincup PH, Morris RW, et al. Aspirin use in middle-aged men with cardiovascular disease: are opportunities being missed? Br J Gen Pract 1997;47:417-21

26 Aronow HD, Topol EJ, Roe MT, et al. Effect of lipid-lowering therapy on early mortality after acute coronary syndromes: an observational study. Lancet 2001;357: 1063-8.

27 Freemantle $\mathbf{N}$, Barbour R, Johnson R, et al. The use of statins: a case of misleading priorities? BM 1997;315:826-8.

28 Pickin DM, McCabe CJ, Ramsay LE, et al. Cost effectiveness of HMG-CoA reductase inhibitor (statin) treatment related to the risk of coronary heart disease and cost of drug treatment. Heart 1999;82:325-32

29 Fairhurst $\mathbf{K}$, Huby $\mathrm{G}$. From trial data to practical knowledge: qualitative study of how general practitioners have accessed and used evidence about statin drugs in their management of hypercholesterolaemia. BM 1998;317:1130-4

\section{Call for peer reviewers}

Clinical Evidence is a regularly updated evidence based journal available world wide both as a paper version and on the internet. Clinical Evidence urgently needs to recruit a number of new contributors. Contributors are health care professionals or epidemiologists with experience in evidence based medicine and the ability to write in a concise and structured way.

Clinical Evidence needs to recruit a number of new peer reviewers. Peer reviewers are health care professionals or epidemiologists with experience in evidence based medicine. As a peer reviewer you would be asked for your views on the clinical relevance, validity and accessibility of specific topics within the journal, and their usefulness to the intended audience (international generalists and health care professionals, possibly with limited statistical knowledge). Topics are usually 2000-3000 words in length and we would ask you to review between 2-5 topics per year. The peer review process takes place throughout the year, and our turnaround time for each review is ideally 10-14 days.

If you are interested in becoming a peer reviewer for Clinical Evidence, please complete the peer review questionnaire at www.clinicalevidence.com or contact Polly Brown (pbrown@bmigroup.com) 